\title{
Growth and Abscission in Sea Island Cotton.
}

\author{
BY
}

T. G. MASON, M.A.,

Economic Botanist and Acting Assistant for Cotton Research, The Imperial Department of Agriculture, West Indies.

With fourteen Figures in the Text.

\section{INTRODUCTION.}

$T$

HE immediate object of the studies reported in the present paper was to obtain information concerning both the external and the internal factors responsible for the premature shedding of the flower-buds and the young fruit (bolls) of the cotton-plant in St. Vincent. The economic importance of premature abscission is not, of course, confined to the cotton-plant, for it is responsible for considerable losses in a large number of cultivated plants. Future investigation may reveal how far the conclusions arrived at in the course of the present work are of wider application.

Before reporting the results, reference should be made to the conclusions of previous investigators of the problem. The work of Balls (1) in Egypt established a strong presumption that the major factor initiating abscission was a marked water-deficit in the body of the plant. It was found that the elongation of the stem of the cotton-plant was checked immediately the sun struck upon it, and that a slight shrinkage usually followed. A cloud passing across the sun, for instance, was effective in permitting growth, which ceased again as soon as the sun emerged. Balls's conclusion that a net loss of water was the direct cause of growth-inhibition and boll-shedding received confirmation from Lloyd's (6) studies, which were conducted under the relatively humid conditions of Alabama. Ewing's (2) work in Mississippi also indicated that a disturbance in the water-balance of the plant was the main factor responsible for shedding. In St. Vincent, where cotton is probably cultivated under more humid conditions than elsewhere, Harland (3) noted that shedding was heaviest after torrential rain. His observations led him to conclude that root absorption was interfered with as a result of the reduction in the oxygen-

[Annals of Botany, Vo1. XXXVI. No. CXLIV. October, 1922.]

$\mathrm{K} \mathrm{k}$ 
supplying power of the soil, and that consequently a water-shortage ensued, which was the immediate cause of shedding.

\section{MATERIAL.}

The work was carried out on the St. Vincent Experiment Station between June I92I and February I922. The first series of observations was made on a group of plants which were sown on June 20 ; this, it may be noted, is approximately the normal time at which cotton is planted in St. Vincent. The second series of observations was made on a group of plants which were not sown till August 27. The environmental conditions which prevailed during the later stages of the development of this group were considerably less humid than in the case of the former.

The June-sown plants which constituted the first group consisted of thirty-five plants distributed at random through a plot of one-tenth of an acre. Two of these were rejected because of damage sustained by wind on September 8. The individual plants in this plot were spaced at intervals of four feet. A daily record was kept for each plant of the rate at which the main axis elongated, of the number of flower-buds and flowers produced on the primary fruiting branches, and of the number of flower-buds and bolls shed. In this group measurements of the length of the main axis were made every day; the number of flower-buds and flowers produced and the numbers shed were not, however, observed on Sunday; these were estimated as far as possible from the observations of the preceding and following days ; one-third of Monday's quota was also credited to Sunday; the adoption of this procedure renders caution essential in interpreting the results. The second group was sown on August 27 and consisted of 749 plants, spaced from 18 to 24 inches apart in rows $4 \mathrm{ft}$. wide. Daily measurements were made of the height of the main axis on thirty-one of these plants, distributed at random throughout the whole population. A daily record was also kept of the number of flowers produced and the bolls shed by all the plants.

\section{THE PROBLEM.}

After the work had proceeded a short time, it became apparent that there were three phases of the problem which merited particular attention: (I) the rôle of the physical environment in initiating abscission, (2) the more pronounced tendency to undergo abscission of both flower-buds and bolls produced during the later part of the flowering period, and $(3)$ the tendency for both flower-buds and bolls to be shed when at a very early stage of development.

The graph in Fig. I illustrates the latter tendency. The results are based on observations which were made on the first group of plants. The 
method adopted in order to determine the age of a flower-bud at shedding requires a word of explanation; the boll presents no difficulties in this respect, for its age can be expressed as the number of days which elapsed between the open flower stage and the completion of abscission. In the case of the flower-bud, however, there is no readily recognizable stage to which its age can be referred. The convention adopted was to express its age at the time of shedding as the number of days which elapsed between the stage in its development which corresponded to the unfolding of the attendant foliage leaf and the completion of abscission; the attendant leaf was judged to be unfolded as soon as the upper surface became clearly visible. The propriety of this procedure is admittedly open to criticism, for it assumes a definite relationship between the development of the bud and

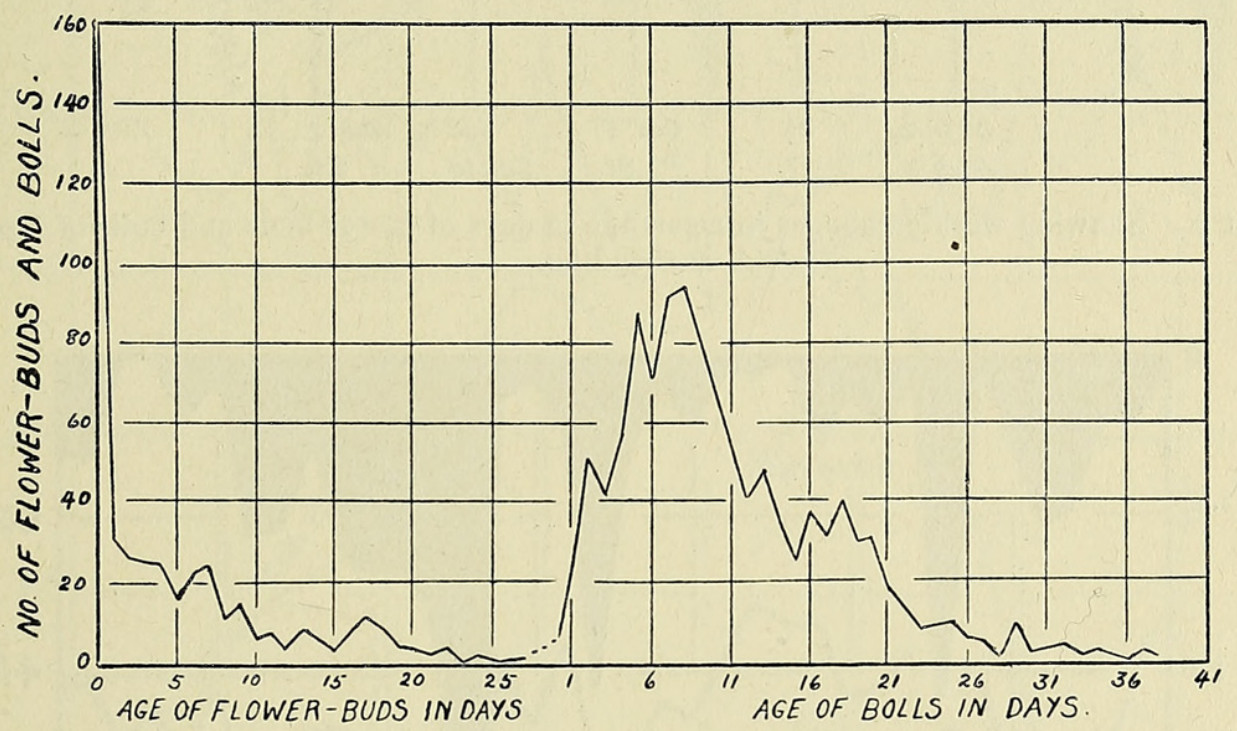

FIG. I. Age frequencies of flower-buds and bolls of Group I at shedding.

its attendant foliage leaf. It will be observed (Fig. I) that the majority of flower-buds were apparently shed on the same day that the attendant foliage leaf unfolded. Two hundred and twenty buds were recorded as being shed on this day, whereas only six cases were observed in which the shedding occurred prior to this. There can be little doubt that the explanation of these observations lies in the fact that a large number of flower-buds were shed before the foliage leaf expanded, but escaped notice owing to their minute size. It may be remarked, however, that a careful inspection will generally reveal the presence of the flower-bud from three to five days preceding the unfolding of the leaf.

It is clear (Fig. I) that there is a very marked tendency for the flowerbuds to be shed when very young, and that they become progressively less liable to suffer abscission as they grow more mature. It is of some interest to observe (Fig. 2) that this tendency becomes more pronounced as the development of the plant advances. 
460 Mason.-Growth and Abscission in Sea Island Cotton.

Referring again to Fig. I, it will be noted that another period of marked susceptibility occurs shortly after anthesis, the vast majority of the

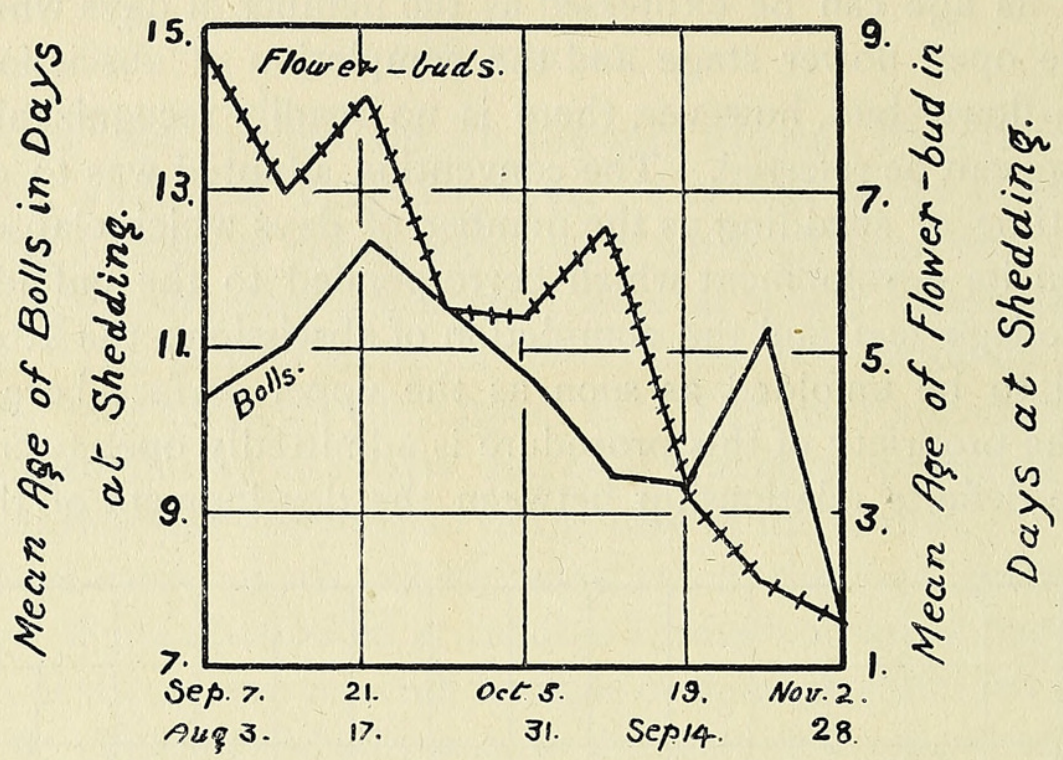

FIG. 2. Showing weekly changes in mean age in days of flower-buds and bolls of Gp. I at shedding.

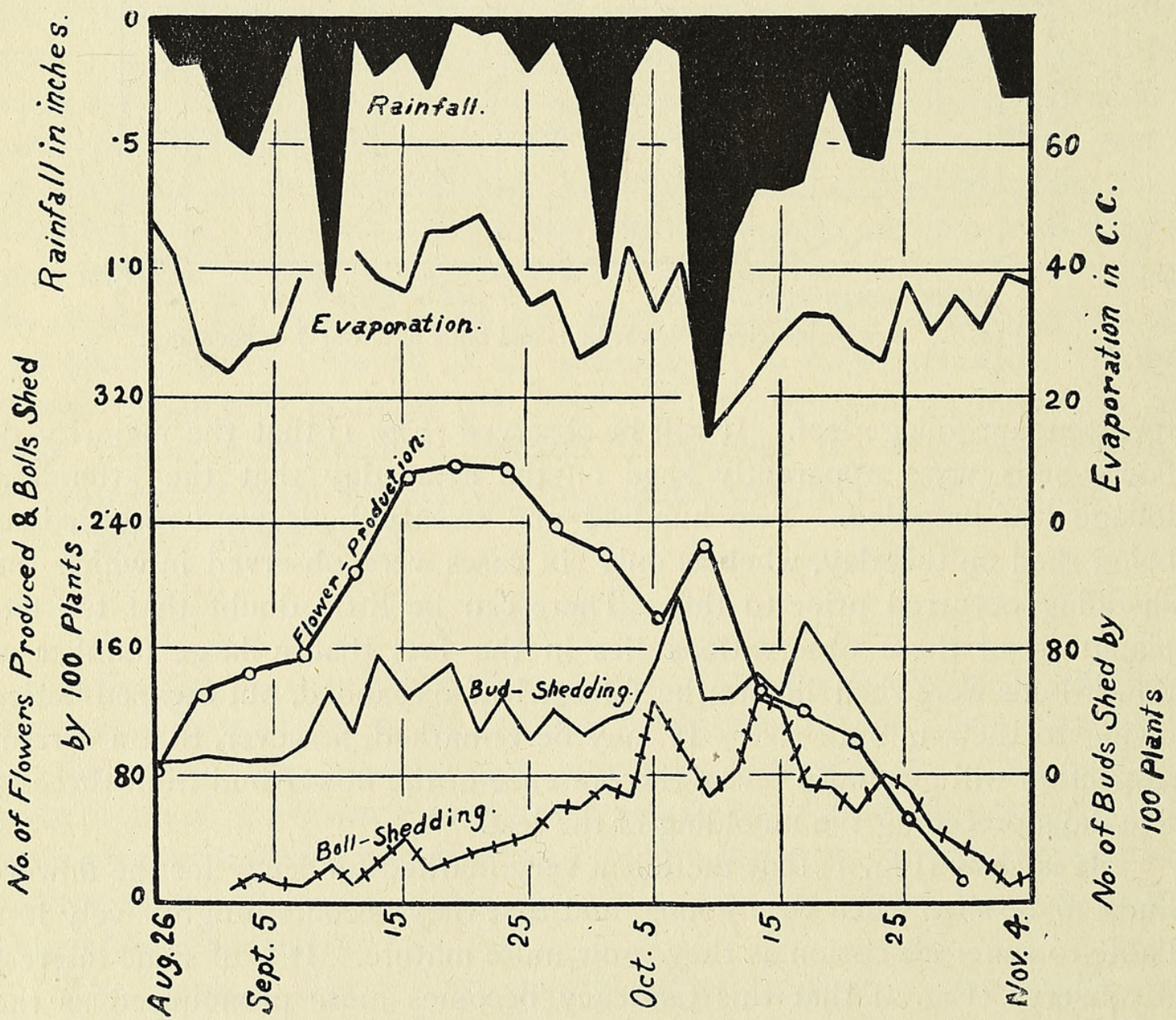

FIG. 3. Rates of flower-bud and boll-shedding, flower production, evaporation, and rainfall. Gp. I. 
bolls being shed when from five to nine days old. A large proportion of the more mature bolls, when shed, were affected with external boll disease (Pseudomonas Malvacearum). It has, of course, long been recognized that both bacterial and fungous diseases of the boll and insect punctures, or any other factor liable to cause injury, increase the susceptibility to shedding.

An indication of the part played by the physical environment in initiating abscission, and the more pronounced tendency of the flower-buds and bolls produced during the later part of the flowering period to undergo

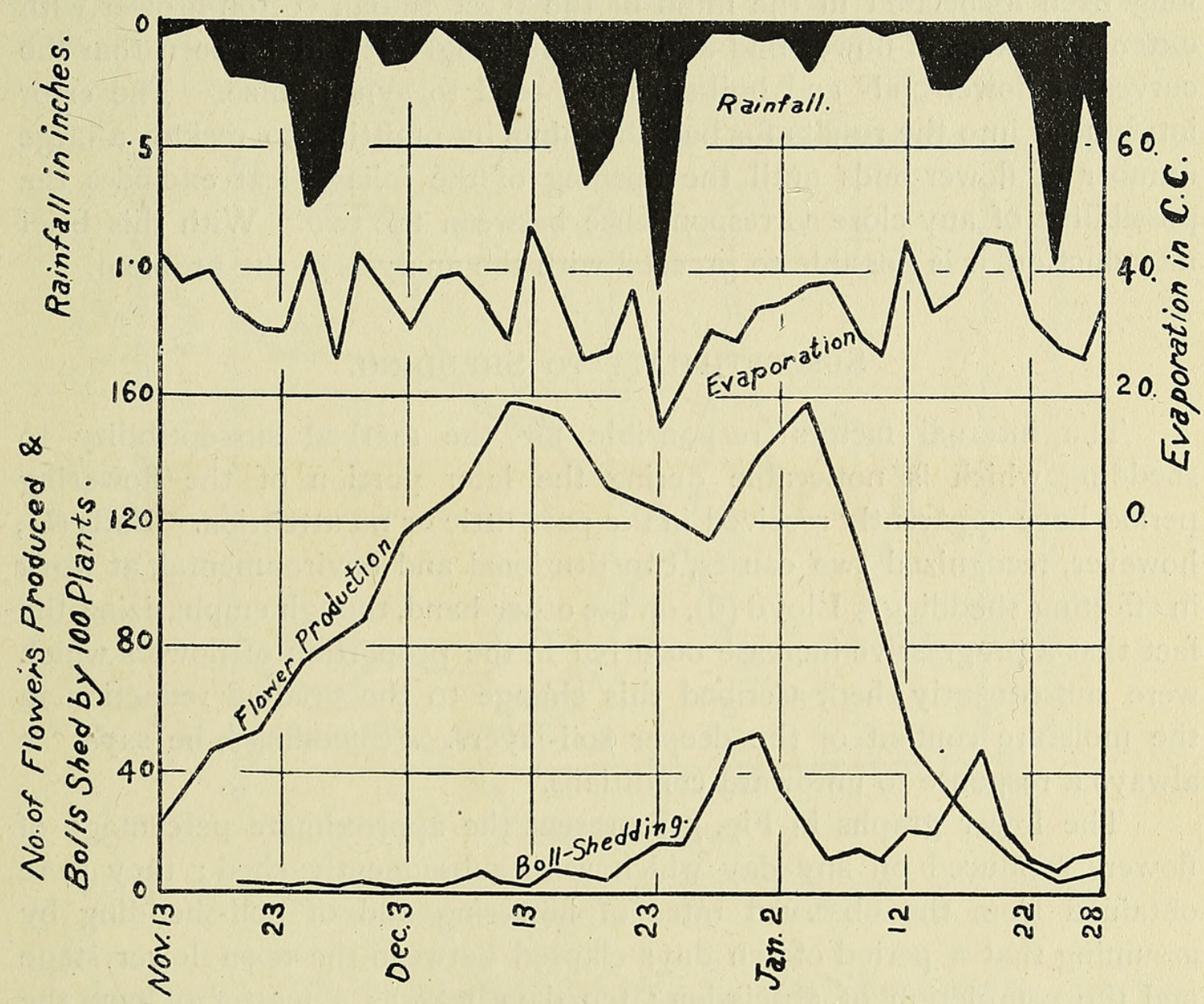

FIG. 4. Rates of boll-shedding, flower production, evaporation, and rainfall. Gp. II.

abscission, can be obtained from the graphs in Figs. 3 and 4. The daily rates of flower production and boll-shedding are exhibited for both groups, but of bud-shedding only for the first group. For comparison with these shedding rates, the evaporation from the Livingston (5) spherical black atmometer and the rainfall have also been inserted. The daily rates of flower production have been smoothed to four-day means, and the shedding rates, evaporation, and rainfall to two-day periods. Attention should be drawn to the small proportion of bolls shed during the earlier portion of the flowering period. The results indicate that quite a small stimulus during the later part of the flowering period may result in a relatively large 
proportion of flower-buds and bolls being shed, and that a stimulus of equal intensity occurring during the preceding period may lead to little or no shedding.

Concerning the nature of the environmental factors which are to be associated with the modes in the shedding curves only the briefest mention is necessary at this stage. The waves of boll-shedding, it may be observed, are generally, but not always, preceded by periods of considerable precipitation and low rates of evaporation. Periods of heavy rainfall have, of course, long been associated in the mind of the West Indian cotton-grower with extensive waves of flower-bud and boll-shedding. It will be seen that the curves of flower-bud- and boll-shedding tend to synchronize. The error introduced into the results for bud-shedding by omitting to reckon a large number of flower-buds until the opening of the foliage leaf excludes the possibility of any close correspondence between the two. With this brief introduction, it is possible to proceed with the analysis of the problem.

\section{Susceptibility to Sheding.}

The internal factors responsible for the marked susceptibility to shedding which is noticeable during the later portion of the flowering period have apparently received in the past little or no attention. Balls (1), however, recognized two causes, constitutional and environmental, at work in effecting shedding. Lloyd (6), on the other hand, though emphasizing the fact that a progressive increase occurred in the proportion of flowers which were subsequently shed, ascribed this change to the gradual reduction in the moisture content of the deeper soil-layers. 'Shedding', he says, 'is always a response to untoward conditions.'

The lower graphs in Fig. 5 represent the approximate percentage of flowers produced on any day which were subsequently shed; they were obtained from the observed rates of flowering and of boll-shedding by assuming that a period of ten days elapsed between the open flower stage and the completion of abscission; ten days was, as a matter of fact, the mean period in the first group; the records of the second group do not, however, permit of an exact estimate being formed. As the results are smoothed to four-day intervals the error introduced by this assumption is not of grave consequence.

The mean daily growth-rates of the main axis of both groups have been smoothed for a similar period and are also reproduced in Fig. 5 . Inspection of the two sets of graphs reveals the fact that the percentage of flowers which subsequently underwent abscission remained relatively insignificant until growth of the main axis had almost ceased. It is difficult to escape the conclusion that the fluctuations in the physical environment which generally herald waves of shedding are not of marked 
importance in initiating abscission until after the inhibition of growth in the main axis.

The results of a recent investigation ( 7$)$ on correlation in the cotton plant is of some interest in this connexion. In the course of that work it was found that the growth-rate of the main axis commenced to decline as soon as boll-development was initiated, and, moreover, that this retardation in the growth-rate could be deferred by suppressing fruit development. It was also demonstrated that growth-cessation in the main axis was not due to any autogenic change within the terminal meristem, for renewed activity of the apparently senescent apical bud occurred after it was isolated and budded on a young plant.

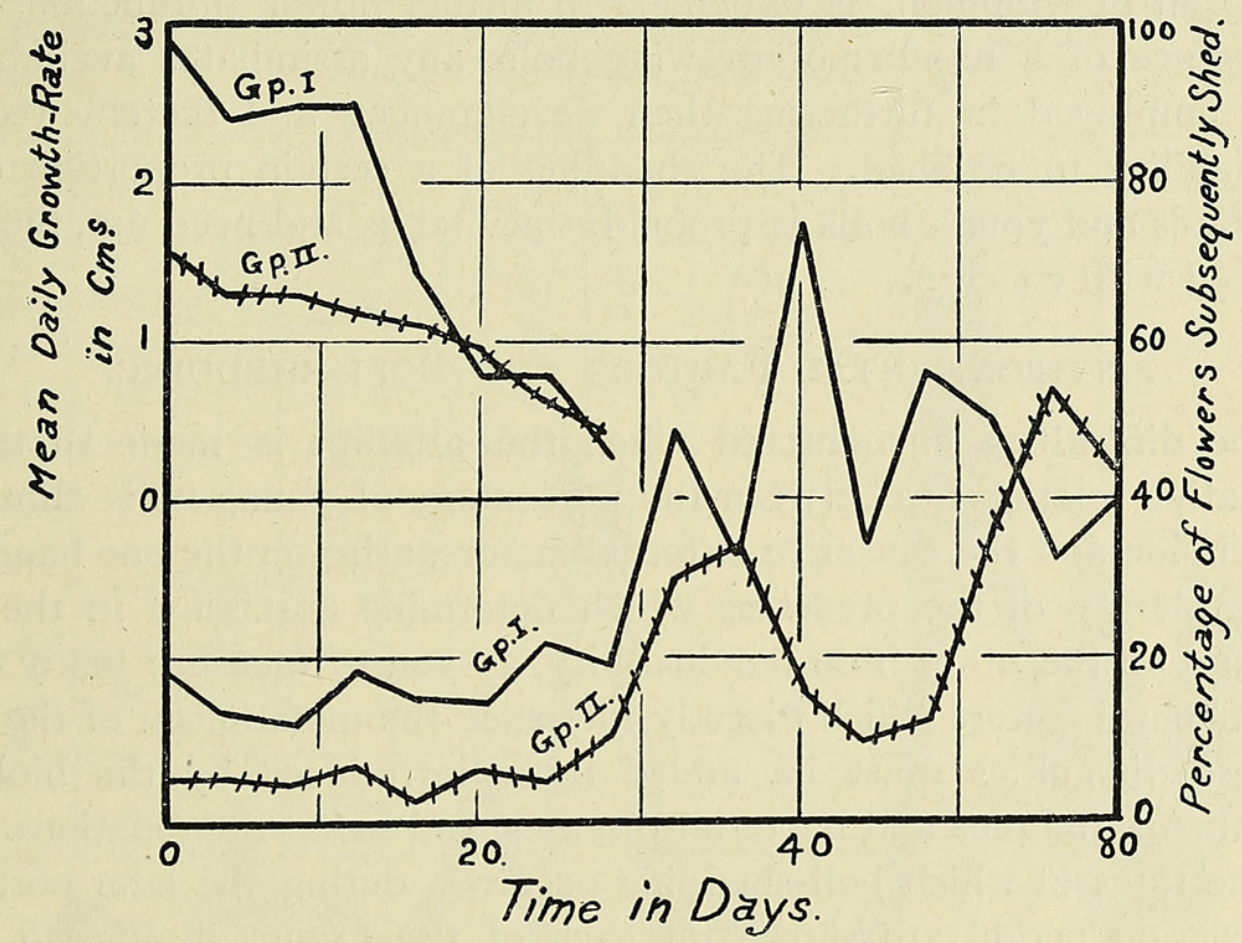

FIG. 5. Percentage of flowers produced daily which were subsequently shed, and daily growth-rates of main axis. Gps. I and II.

As a result of these and other observations, which need not be repeated here, it was concluded that the decline in the activity of the apical meristem was due to a correlation factor, which was introduced by the development of fruit on the basal fruiting branches. It was suggested that it was in some way to be associated with a deflexion of growth-promoting substances, especially carbohydrates, from the apical to the basal part of the plant.

It seems plausible to infer that the greater liability of bolls, produced after growth-cessation has taken place in the main axis, to undergo abscission may also be associated with a deflexion of assimilates from the apical to the basal fruiting branches, for the major part of the fruit produced during the latter part of the flowering period is, of course, situated on the apical part of the plant. Should this assumption be warranted, it would 


\section{Mason.-Growth and Abscission in Sea Island Cotton.}

follow that the incidence of any external growth-retarding factor would lead to a check in the rate at which elaborated food was being produced, and the consequent reduction in the supply of assimilates might well furnish, either directly or indirectly, the stimulus for augmented rates of shedding.

The hypothesis is supported by an experiment made by Ewing (2) in Mississippi, in which it was found that the daily removal of all the flowers almost doubled the amount of flowering, but that the destruction of onehalf of the flowers produced during the last six-tenths of the flowering period led to a scarcely appreciable increase in the flower production; it did, however, almost completely offset the natural tendency to shedding. Presumably the supply of assimilates liberated as a result of the suppression of the fruit development is expended in further flower production, but in the presence of a number of growing bolls any assimilates available are mainly employed in furthering their development, and thereby reducing their liability to be shed. The shedding of a certain proportion of the flower-buds and young bolls is probably inevitable, and need not, therefore, be viewed with concern.

\section{Environmental FaCtors and Boll-Shedding.}

The difficulties encountered when the attempt is made to trace a quantitative relationship between the percentage of young bolls eliminated by abscission and the causative external factors, arise on the one hand from the complexity of the processes which determine abscission in the plant body, and on the other from our inability, as yet, to measure many of the environmental factors which directly influence the metabolism of the plant. To these difficulties must be added those introduced by the biological environment, fungous and bacterial diseases, and insect depredations.

The rates at which boll-shedding occurred during the later portion of the flowering period are shown for each of the groups in Figs. 6 and 7 respectively. In the first group, it will be remembered that the number of bolls which were shed on Sundays was not directly determined, and that one-third of Monday's quota was credited to these days, which are indicated on the graphs by the solid black circles. A word of explanation is also needed concerning the environmental factors of which records were kept, and the method of their presentation.

Evaporation from the Livingston spherical atmometers, both black and white, was measured daily in duplicate at 9 a.m.; the difference is represented in the figures as 'Evaporation due to solar radiation', whereas 'Evaporation' refers to the total evaporation from the black atmometer. 'Daytime rain' indicates the amount of precipitation which occurred between 9 a.m. and 3 p.m.; it therefore represents the rainfall occurring during the hottest part of the day. A daily record of the temperature, both of the subterranean and aerial environments, was also kept, but, owing to the small 
Mason.-Growth and Abscission in Sea Island Cotton. 465

amount of variation and the apparent absence of any significant relationship, it has not been reproduced.

The environmental factors have been displaced five days to the left in each of the figures. Such a procedure, of course, assumes that a constant interval of approximately five days intervenes between the incidence of the causative factor and the completion of abscission. It was found, however, that by doing this a reasonably close correspondence could be traced between certain external factors and the major waves of boll-shedding. Ewing's studies, too, it may be noted, indicated that five to six days represented

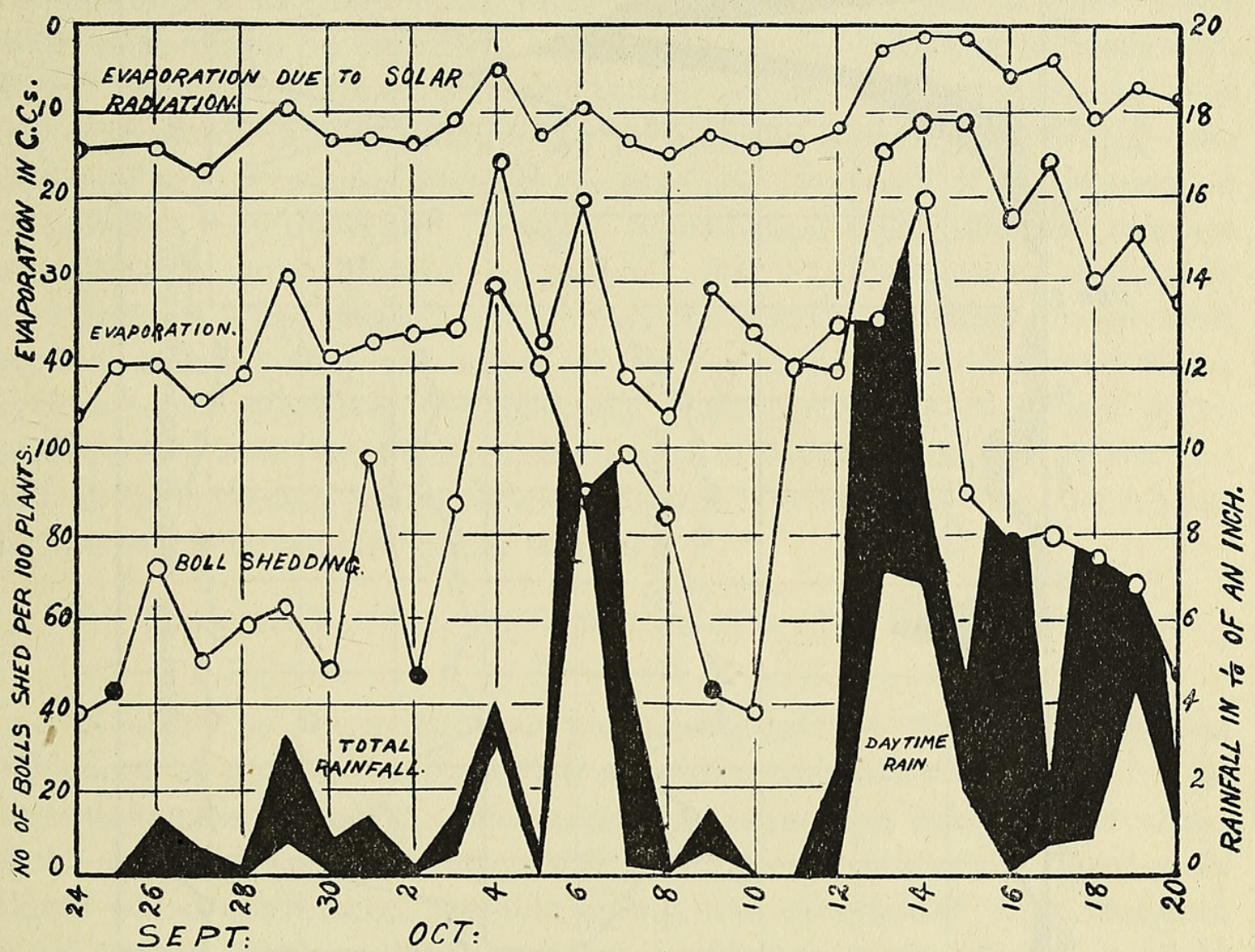

FIG. 6. Daily rates of boll-shedding, rainfall, evaporation, and evaporation due to solar radiation. Gp. I.

under natural conditions the mean interval between the stimulus and the abscission response, while Lloyd's work in Alabama pointed to an approximately similar period.

Reference to Fig. 4 will show that the two main waves of shedding (commencing October 2nd and loth respectively) were both preceded by periods of heavy daytime rain and low rates of evaporation. To the minor waves, commencing October 26 , no significance can be attached, for the probability exists that they would have been eliminated had the population been larger. In Fig. 7, for instance, which shows the results for the 749 plants of the second group, these minor irregularities are almost 


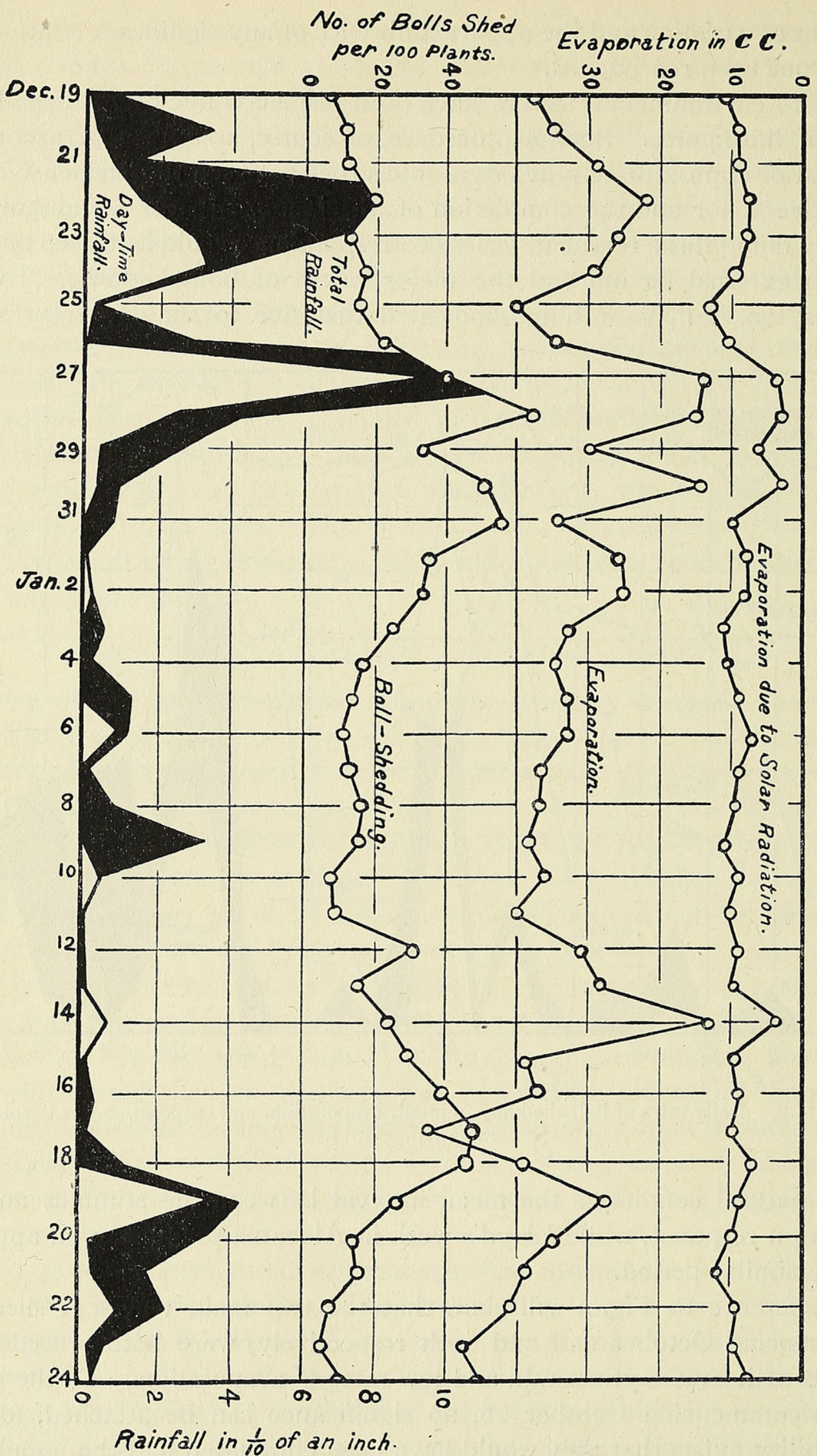

FIG. 7. Daily rates of boll-shedding, rainfall, evaporation, and evaporation due to solar radiation. Gp. II. 
completely removed. Here, too, it will be seen, the first shedding wave (commencing December 26) followed five days after a period of heavy daytime rain and low rates of evaporation. The second wave, it will be noted, followed some five days after a change from very low to rather high evaporation rates. It will be remembered, however, that the probability exists that a very slight stimulus during this later portion of the flowering period may initiate shedding, and that even in the absence of a stimulus of any sort a certain amount of shedding is apparently inevitable.

To sum up, the results suggest that heavy rainfall is not directly responsible for the augmented rates of shedding; nor yet, it would seem, is daytime rain to be especially associated with the initiation of abscission. It will be observed, however, that daytime rain when accompanied by very low evaporation rates is followed by pronounced shedding. That daytime rain may have occasioned some of the shedding as a result of the destruction of pollen is very probable. A more fundamental cause than the absence of pollination must, however, be sought. For it cannot but be significant, as Harland (3) has pointed out, and as the results presented in the next section indicate, that the waves of bud- and boll-shedding tend to be synchronous. Moreover, the relatively small percentage of flowers which subsequently underwent abscission, in spite of daytime rain, during the first half of the flowering period clearly indicates how slight is the part played by this factor in bringing about shedding.

\section{The Growth-Rate of the Main Axis and Environmental} FACTORS.

In order to determine how the growth-rate of the main axis was influenced by daytime rain and low rates of evaporation, which the results presented in the preceding section seemed to suggest as being the precursors of the augmented rates of boll-shedding, the growth-rate of the thirty-three plants which constituted the first group was determined daily, between 9 and II a.m., until growth became so small that no significance could be attached to the daily variations. The measurements were made from the cotyledonary node to the terminal bud. In Fig. 8 the mean results of these measurements for a period of forty days are presented for comparison on the one hand with rainfall and evaporation, and on the other with the rates of bud-and boll-shedding. Inasmuch as some of the flower-buds were shed before the opening of the attendant foliage leaf, and consequently the day on which they were shed is not known, only those which were shed subsequently have been included in the results presented in Fig. 8.

Inspection of the graphs betrays the somewhat remarkable fact that low rates of evaporation accompanied, as is generally the case, by daytime rain corresponded with a marked retardation in the growth-rate. The amount of evaporation on September 8 and 9 was not determined, as the 
atmometers were dislodged by the wind; evaporation was, however, as may be inferred from the amount of daytime rain, very small on the 8 th, and also on the 9th. The tardiness in the rates of recovery of the growth-rate at this time was partially due, no doubt, to root injury sustained as a result of the wind, but was mainly, as reference to Fig. 4 indicates, due to the normal decline in the growth-rate occasioned by the augmentation in the number of the developing fruits. This conclusion is sustained by the rapidity with which some young plants in a neighbouring plot recovered. The plants were not measured on the 8 th, so that the growth-rates for this and the following day have been taken as the mean of the two-day period.

Referring again to Fig. 8 , it will be seen that a wave of bud-shedding occurred 4-5 days, and of boll-shedding 5-6 days after September 8 . The shedding waves which took place on the 7 th, 8 th, and 9 th of the same month commenced six days later than the retardation in the growth-rate of the main axis which occurred on the Ist. The comparative absence of shedding during the earlier part of the period is not only ascribable to the paucity in the number of flower-buds and bolls, but also to their very slight liability to undertake the abscission response at this period.

It will be evident that no definite relationship can be traced between the daily fluctuations in the growth-rate of the main axis and the amount of shedding which ensued. The results, nevertheless, indicate a strong probability that the same external factors-to wit, daytime rain and low rates of evaporation - which cause a retardation in the growth-rate during the earlier periods of the plant development, are also responsible for the extensive shedding of bolls which occurs during the later portion of the flowering period. It would follow, if this view is correct, that the same internal factors are the cause of both phenomena. As yet the relative importance of these various internal factors cannot be diagnosed, for daytime rain and the reduction in light intensity which accompanies low rates of evaporation might retard not only the rates of carbon assimilation, but would also lead to large turgor pressures (possibly attended by incipient guttation), which would limit the supply of electrolytes normally translocated with the transpiration current; the net result would presumably be a check in the supply of elaborated food. It is also conceivable that the translocation of assimilates might be inhibited by the augmentation in the turgor pressure.

The difficulty encountered when the attempt is made to ascertain whether or no the extent of the daily fluctuations in the growth-rate is directly related to the amount of boll-shedding arises of course from the fact that throughout the period of greatest susceptibility to shedding the growth of the main axis has practically ceased. At first sight it might appear feasible to bridge this gap by determining whether the amount of 


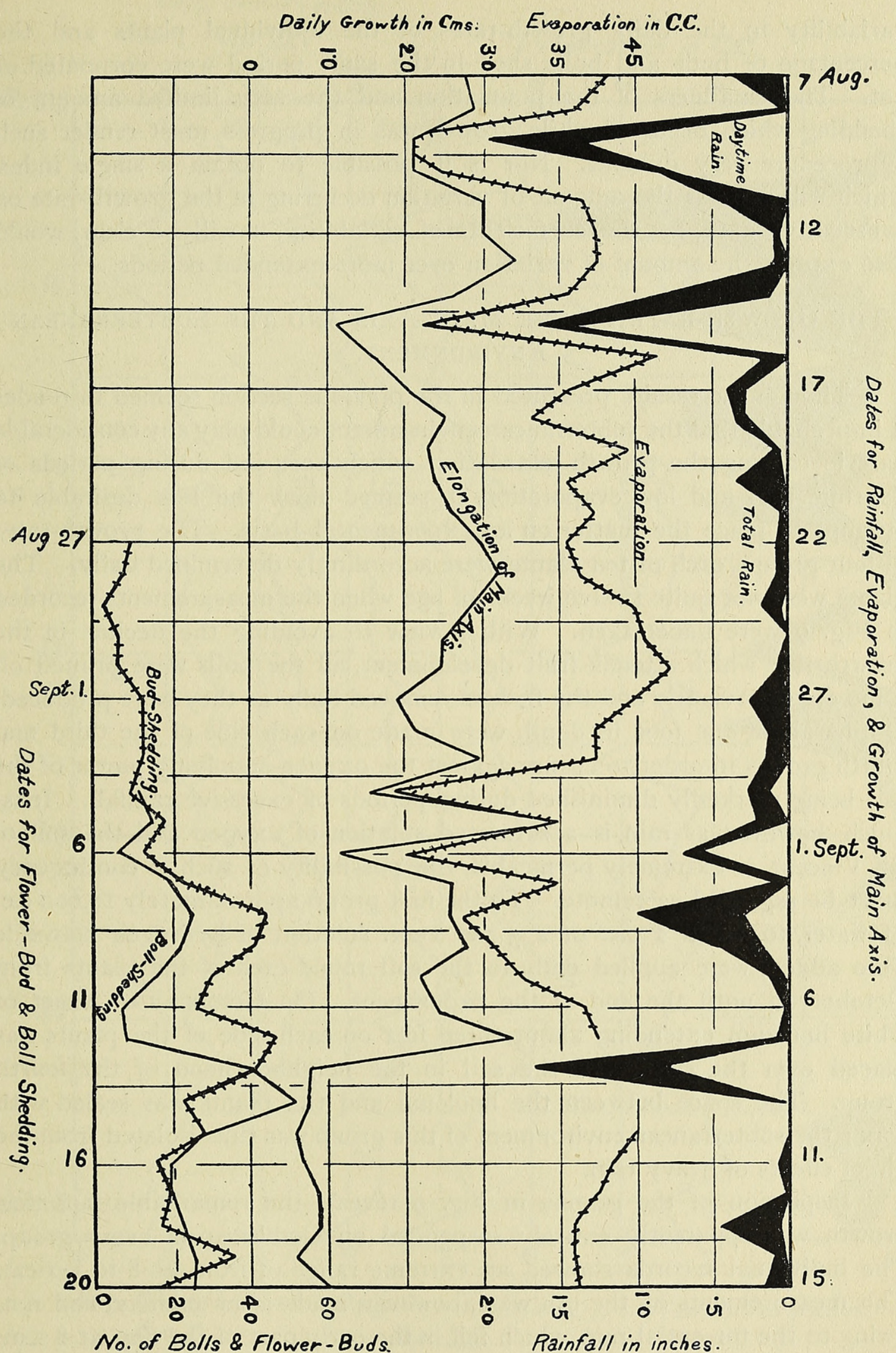

No. of Bolls \& Flower-Buds. shed.

Fig. 8. Daily rates of flower-bud and boll-shedding, axis elongation, evaporation, and rainfall. Gp. I. 
variability in the daily growth-rates of the individual plants and the percentage of buds and bolls shed in the same period were correlated or not. The smallness of the population and the very limited amount of shedding which occurred while growth was in progress must render such a procedure very dubious. Nor is it possible to obtain a single index which will express the amount of variation occurring in the growth-rate on consecutive days, for the coefficients of variability, it will be clear, would also express the amount of variation over more extended periods.

\section{The Growth-Rate of the Main Axis and the Subterranean ENVIRONMENT.}

Though the results presented in the previous section seemed to render it improbable that the subterranean environment could play any considerable part in causing the growth-retardation which occurred during periods of daytime rain and low evaporation, it seemed none the less desirable to attempt to place the matter on an experimental basis. The growth-rates of four groups, each of ten plants, were accordingly determined daily. The plants were not quite twelve weeks of age when the measurements recorded in Fig. 9 were undertaken. With a view to avoiding the decline in the growth-rate which attends fruit development, all the bolls were pruned off some days previously and the flowers removed daily as they were produced. Drains about one foot in depth were made on each side of the third and fourth groups in order to ensure against the oxygen-supplying power of the soil being markedly diminished during periods of excessive rainfall. Inasmuch, however, as rain is a saturated solution of oxygen and the soil of St. Vincent is extremely permeable, the possibility of such a contingency must be regarded as remote. To the first group approximately Io,000 c.c. of water, to which 2 c.c. of a 3 per cent. solution of hydrogen peroxide were added, were applied daily to the soil round each of the plants from October 17 until the end of the experiment. On October 16 a sheet of white linoleum extending about three feet on each side of the plants was placed over the surface of the soil in the neighbourhood of the fourth group. The space between the linoleum and the plants was sealed with wax; the subterranean environment of this group was thus isolated from the direct effects of heavy rain.

Inspection of the graphs in Fig. 9 reveals the remarkable fact that growth was apparently entirely suspended on October 9 in every group. The individual records showed an extreme range of from -0.8 to $1 \cdot 0 \mathrm{~cm}$. The measurements on the 9 th were, however, made after midday, and not, owing to the torrential rain, which fell in the early part of the day, at 8 a.m. as usual. The net result of this delayed measurement may have been to diminish somewhat the growth credited to the 9 th, and to have augmented that of the 8 th. 
Daily Growth in Cms.

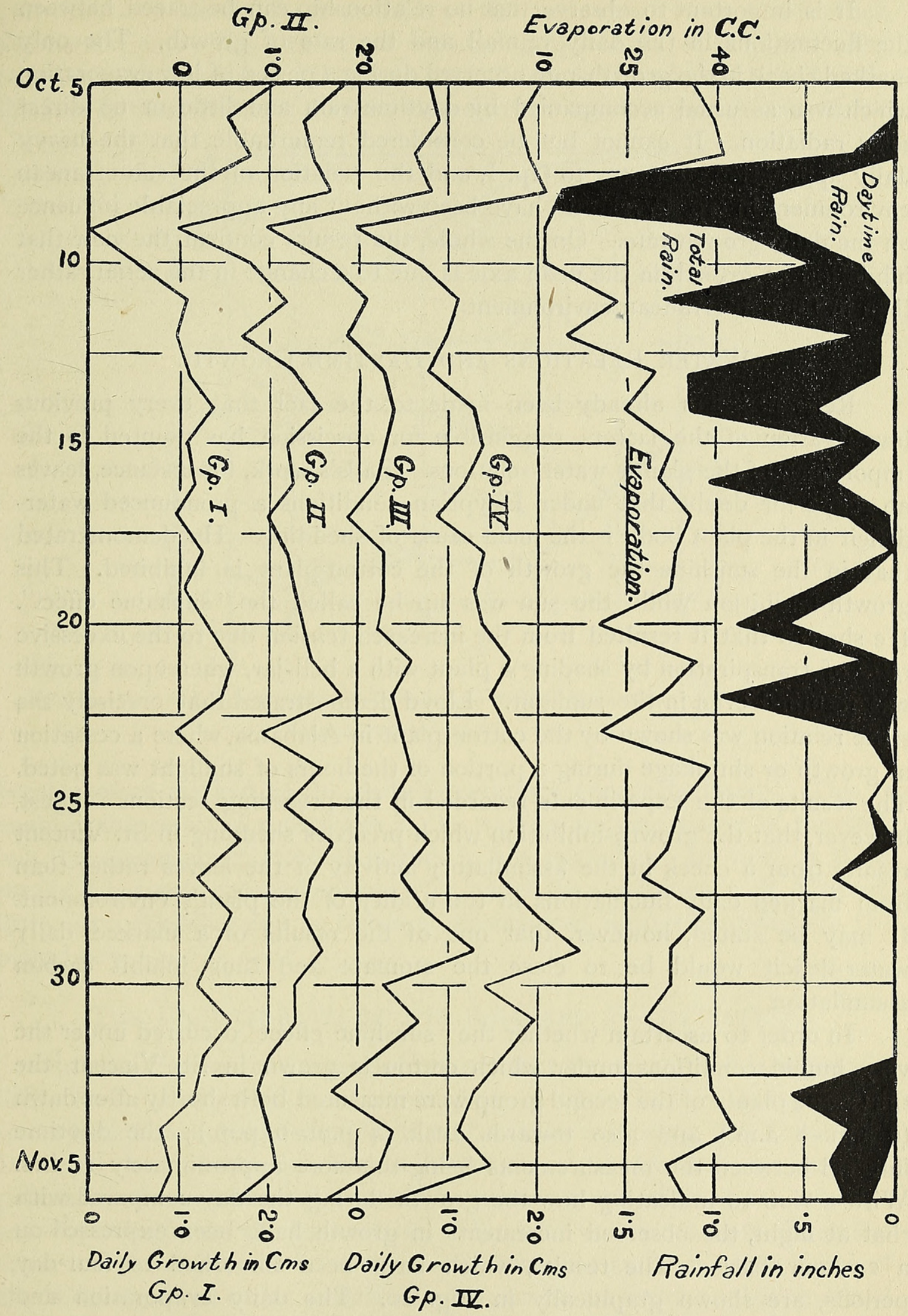

FIG. 9. Daily growth-rate of four groups of plants. Evaporation and rainfall. Gp. I. Not drained. Io,000 c.c. of water, 2 c.c. of 3 per cent. $\mathrm{H}_{2} \mathrm{O}_{2}$ added daily from October $\mathrm{I} 7 . \mathrm{Gp}$. II. Not drained. Gp. III. Drained. Gp. IV. Drained. Linoleum sheet placed on soil on October $\mathbf{I} 6$. 


\section{Mason.-Growth and Abscission in Sea Island Cotton.}

It is important to observe that no relationship can be traced between the fluctuations in the daily rainfall and the rate of growth. The only marked check in the growth-rate occurred during a period of low evaporation which was as usual accompanied by daytime rain and little or no direct solar radiation. It cannot but be considered remarkable that the heavy daily application of water to Gp. I, and the isolation of the subterranean environment in Gp. IV, should have been without any appreciable influence on the daily growth-rate. On the whole, the results confirm the view that inhibition of growth in the main axis is due to a change in the aerial rather than in the subterranean environment.

\section{Water Relations and Daytime Growth.}

Reference has already been made to the fact that every previous investigation of the factors responsible for abscission has pointed to the importance of the plant's water relations. Balls's work, for instance, leaves no scope for doubt that under Egyptian conditions a pronounced waterdeficit in the plant body is the main cause of shedding. He demonstrated that in the sunshine the growth of the cotton-plant is inhibited. This growth-inhibition while the sun was up he called the 'sunshine effect'. He showed that it resulted from the increased tension due to the excessive rates of transpiration by shading a plant with a bell-jar, whereupon growth was resumed even in the sunlight. Lloyd demonstrated that precisely the same relation was shown by the cotton-plant in Alabama, where a cessation of growth or shrinkage during a portion of the hours of sunlight was noted. The results of the experiments recorded in the preceding sections suggest, however, that the growth-inhibition which precedes shedding in St. Vincent results from a check in the assimilatory activity of the leaves rather than from marked daily fluctuations in the aridity of the plant's environmont. It may be stated, however, that one of the results of a marked daily water-deficit would be to close the stomata and thus inhibit carbon assimilation.

In order to ascertain whether the 'sunshine effect' occurred under the very humid conditions under which cotton is grown in St. Vincent, the thirty-one plants of the second group were measured both shortly after dawn (6 a.m. -8 a.m.) and also towards dusk (4 p.m.-6 p.m.); the daytime interval between the measurements being therefore approximately io hrs. With a view to indicating how the growth during the day compared with that at night, the observed increments in growth have been expressed on a 24-hour basis. The results, which have been smoothed to four-day periods, are shown graphically in Fig. 10. The daily evaporation and rainfall, smoothed for a similar period, are also reproduced in the figure. Inspection of the graph discloses the fact that growth was inhibited to only a very small extent during the hours of sunshine. Some retardation in the 
growth-rate is inevitable as a result of the augmented water strain which attends the more rapid ascent of sap during the hours of sunlight. The ratio between the day and the night growth-rate is also shown in the figure; this is of interest in that it demonstrates that the daytime growth-retardation

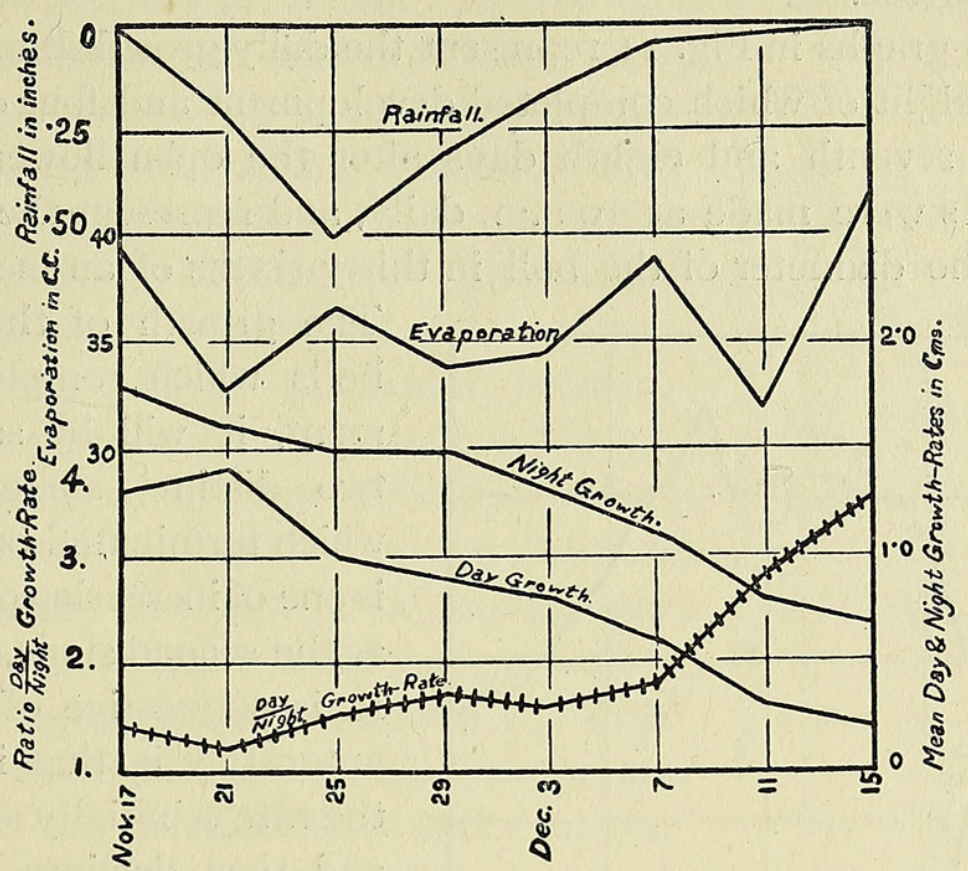

FIG. 10. Day and night growth-rates brought to a 24 hour basis, ratio $\frac{\text { day }}{\text { night }}$ growth-rate, evaporation, and rainfall. Gp. II.

became more marked as the daily growth-rate approached zero. This is possibly the result of a decrease in the water-supplying power of the soil, but the operation of internal factors is not excluded. In view of these results it becomes comprehensible why, under the conditions in St. Vincent, little or no shedding can be traced to pronounced saturation-deficits in the plant body.

\section{The Growth-Rate of the Boll and Fertilization.}

In an earlier section it was pointed out that the young boll is especially liable to be shed when about seven days of age. This in the past has sometimes been considered indicative of a factor inhibiting fertilization (1). It would seem impossible normally to associate this with unsuccessful pollination, for the interval elapsing between the reception of the stimulus and the completion of abscission is under field conditions only about five days. Moreover, it will be remembered that the more constant cause of shedding appeared to be associated with conditions which tended to retard the growth of the plant as a whole rather than with the influence of daytime rain on individual flowers. It seems legitimate to infer that the metabolic transformations which precede abscission, and which probably in 
some way inhibit fertilization, or, what is more probable, inhibit the stimulus to fruit development. are especially liable to be initiated some days after rather than during the open flower stage. The results of some measurements of the growth-rate of the bell, which seem to bear on the point, will now be considered.

The two graphs in Fig. I I represent the daily growth-rates of forty-two bolls, thirty-eight of which completed development and four of which were shed on the seventh and eighth days after the open flower stage. The measurements were made at 10 a.m. daily, and represent the daily rate of increase in the diameter of the boll in thirty-sixths of an inch $(0.71 \mathrm{~mm}$.).

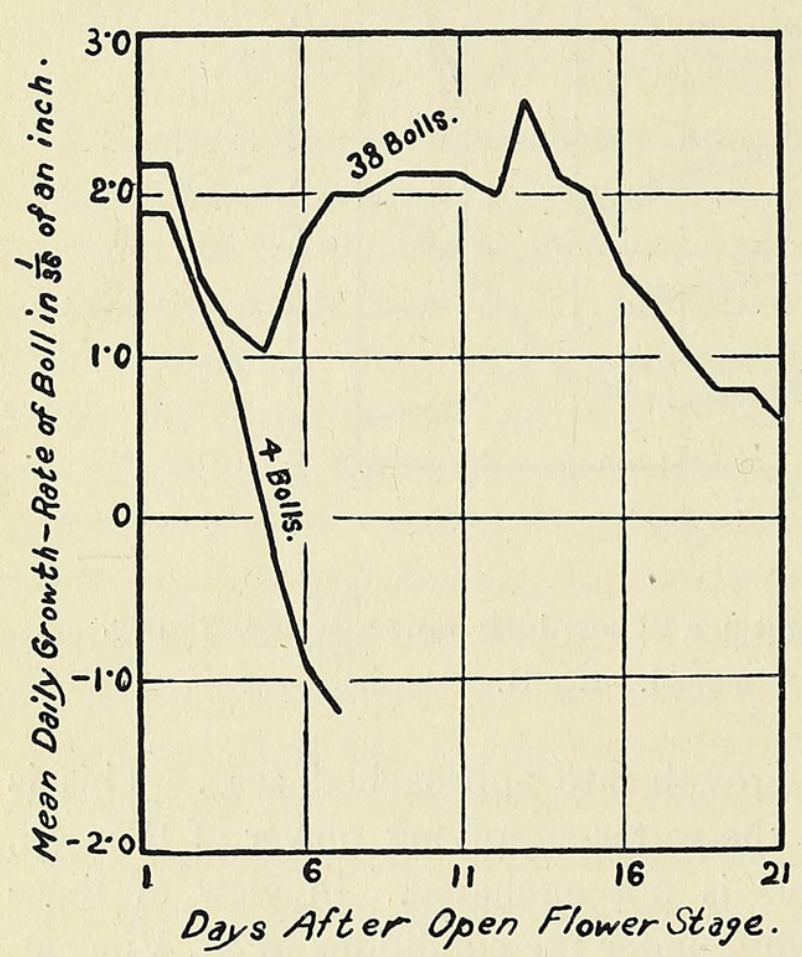

FIG. II. Showing the two stages in the growth of a boll.

The growth of the thirty-eight bolls which completed development, it will be seen, falls into two distinct stages. The first, which terminated on the 5 th day, is one of increasing growth, whereas the second stage, which follows it, is suggestive of the curve of autocatalysis, that is to say that the rate is initially slow, increases, and then declines. Comparison with the growth of the four bolls which were shed on the 7 th and 8 th days shows that the first stage is essentially similar in both, but that in the latter recovery failed to occur. It is certainly very suggestive that the period which other considerations point to as the period of greatest susceptibility to the stimulus which initiates abscission should be also one of growth-retardation. It will be remembered that the period of greatest susceptibility to shedding did not occur until after the inhibition of growth in the main axis, and that the same external factors which were associated with a retardation in the growth-rate of the main axis also preceded augmented rates of shedding.

The next point which calls for comment is the rôle played by fertilization. Balls, it will be recalled, has pointed out that fertilization in the cotton-plant is normally completed within thirty hours after the opening of the flower, i. e. by the afternoon of the following day. If recovery in the growth-rate on the fifth or six days after the open flower stage is dependent on fertilization, it is an interesting fact that a delay of 4-5 days should occur between the completion of fertilization and the transmission of the 
stimulus to fruit development. In order to ascertain whether this was so or not, two lots, each of twenty-five flowers, were tagged. The stamens were removed from both lots on the day preceding the opening of the flower. On the following day one lot was pollinated and the corollas of both lots were closed with string. All the bolls which had been pollinated completed development, whereas twenty-two of the non-pollinated lot were subsequently shed. The three bolls of the latter lot which were not shed appeared to have normally developed seeds, and therefore presumably had been pollinated, possibly by ants or thrips entering at the base of the flower between the petals. Inspection of the graphs in Fig. 12 will show that recovery from the initial decline in the growth-rate is dependent on the stimulus communicated by fertilization, for though only thirteen of the bolls which were shed are represented in the figure, yet none showed any indication of recovery. The conclusion seems justified that the pronounced liability of the boll to be shed when about seven days old is associated with the growth-retardation which occurs for some days following the open flower stage, and that this in turn is due to the lag

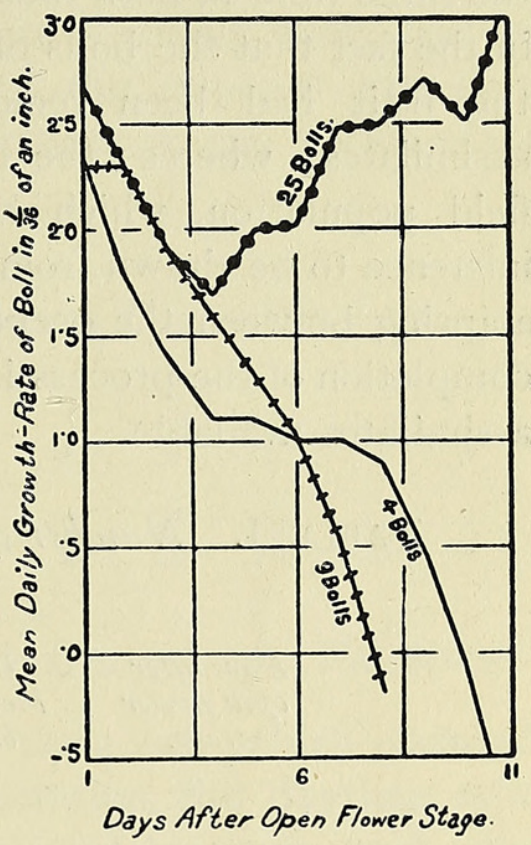

FIG. I 2. Showing recovery in the growth-rate of the boll due to stimulus of fertilization. which occurs between the completion of fertilization and the communication of the stimulus for fruit development. The metabolic transformations which precede abscission are apparently initiated during this critical period of growth-retardation, and doubtless in some way inhibit the stimulus to augmented growth arising from the process of fertilization. The tendency of the flower-buds to be shed at a very early stage of development is conceivably also to be attributed to the slow rate of growth at that time, though no direct evidence in support of this view is obtainable. It will be observed that the assumption has been made that the growth-rate is an index to the rate of metabolism or physiological activity, and that low rates of metabolism render the flower-bud or boll especially liable to undergo abscission. A more extended discussion of this point will be deferred until the results of some additional experiments have been presented.

\section{Abscission and the Supply of Assimilates.}

The ages of two lots of bolls at shedding, one of 2.5 and the other of 30 , are shown in Table I. The growth-rates of 13 of the first lot were considered in the preceding paragraph (Fig. I2). Pollination was prevented in both lots by the removal of the stamens on the day prior to flowering. 


\section{Mason.-Growth and Abscission in Sea Island Cotton.}

It will be seen that the age of the first lot at shedding was markedly greater than that of the second, which in this respect was just about normal. The question which presents itself is, Why should the completion of abscission have been delayed to such an extent in the first lot? for the stimulus to abscission, in the absence of fertilization, must have come into operation at the same time in both lots. There is little doubt that the explanation lies in the fact that the bolls of the first lot belonged to plants from which all the fruit had been removed, thus augmenting the normal supply of assimilates, whereas the bolls of the second lot belonged to an ordinary field population, which had received no treatment of any kind. The inference to be drawn from this experiment is presumably that the interval elapsing between the occurrence of the factor initiating abscission and the completion of the process is determined in a large measure by the supply of assimilates available.

\section{TABLE I. Number of Bolls shed on Successive Days after Open} Flower Stage.

Days after
open flower
stage.
9
10
11
12
13
14
15
16
17
18
19
20

Lot I. Bolls.
Flowers and other
bolls removed.
4
5
2
2
-
-
$\frac{2}{-}$
-

Day after
open flower
stage.
3
4
5
6
7
8
9
10
11
12
13
14

Lot II. 30 bolls.

\begin{tabular}{r} 
I \\
\hline 1 \\
5 \\
10 \\
8 \\
4 \\
I \\
- \\
- \\
-
\end{tabular}

In the course of the preceding pages, it will be recalled, the hypothesis was advanced that the progressive increase in the susceptibility to shedding resulted from the fact that the rate at which food is elaborated by the plant tends to lag behind the rate at which it is utilized by the developing fruit, and that any retardation in the rate of food elaboration results in augmented. rates of shedding. Professor Farmer suggested that it might be instructive to observe the effect on shedding of cutting off the supply of assimilates. Exposure of plants at different stages of development to an atmosphere devoid of carbon dioxide for definite periods would have been the most satisfactory method of doing that, but the experiment was not found to be practicable; removal of the foliage leaves was accordingly resorted to. The plants selected for the experiment had at the time a number of maturing bolls. A number of flowers (33I) were tagged on three successive days and the leaves removed from approximately half the plants on the fourth day. Accordingly, at the time of the operation, the bolls ranged from one 
to four days in age. The results, which are recorded in Table II, show that 96.5 per cent. of the bolls were shed within nine days from the plants which had been deprived of their leaves, and that only $39^{\circ} 6$ per cent. were lost by the control plants in the same period. Of great importance is the fact that the maximum rate of shedding occurred on the fifth day after the operation; the period intervening between the application of the stimulus and the completion of abscission was thus similar to that occurring under natural conditions. The rapidity and completeness of the response can only indicate, moreover, that the reserve food substances in the cotton-plant quickly become exhausted.

\section{TABLE II. Number of Bolls shed on Successive Days after Open} Flower Stage.

$\begin{array}{llrrrrrrrr}\begin{array}{l}\text { Days after open flower stage on } \\ \text { which shedding occurred }\end{array} & \text { I } & 2 & 3 & 4 & 5 & 6 & 7 & 8 & 9 \\ \text { I } 72 \text { Bolls. Leaves removed } & \text { I } & 4 & 13 & 22 & 47 & 38 & 29 & \text { I I } & \text { I } \\ \text { I } 59 \text { Bolls. Leaves not removed } & \text { I } & 2 & 5 & & 6 & 14 & \text { I6 } & \text { I0 } & 6\end{array}$

\section{The Growth-Rate of the Boll and Environmental FaCtors.}

The retardation in the growth-rate of the main axis, which occurred during periods of low light intensity, low evaporation, and daytime rain, conditions which it will be recalled were also followed by augmented rates of shedding, suggested the possibility that these conditions might also be recorded by a check in the growth-rate of the boll.

The growth-rate of three lots of bolls, none of which was shed, are shown in Fig. I3. There were twenty-one bolls in the first lot, thirty-eight in the second, and forty-six in the third. The results represent the mean growth-rates for each lot. Evaporation and rainfall are also shown for comparison with the growth-rates. The environmental conditions which prevailed on October 8 th, 9 th, and 1oth were possibly responsible for the fact that recovery in the growth-rate of the first lot did not take place until the seventh day after the open flower stage. Moreover, it may not be a coincidence that the decline in the growth-rate of the second lot was particularly marked during the same period. It will also be observed that the growth-retardation following anthesis was less pronounced in the third lot than in the first two, and that this synchronized with higher rates of evaporation and only a relatively small amount of daytime rain. It is rather remarkable that the growth-rates of all the three lots should have been greatly augmented on October 18 . The results, though not decisive, nevertheless suggest that the same external conditions which retard the growth of the main axis also depress that of the boll. 


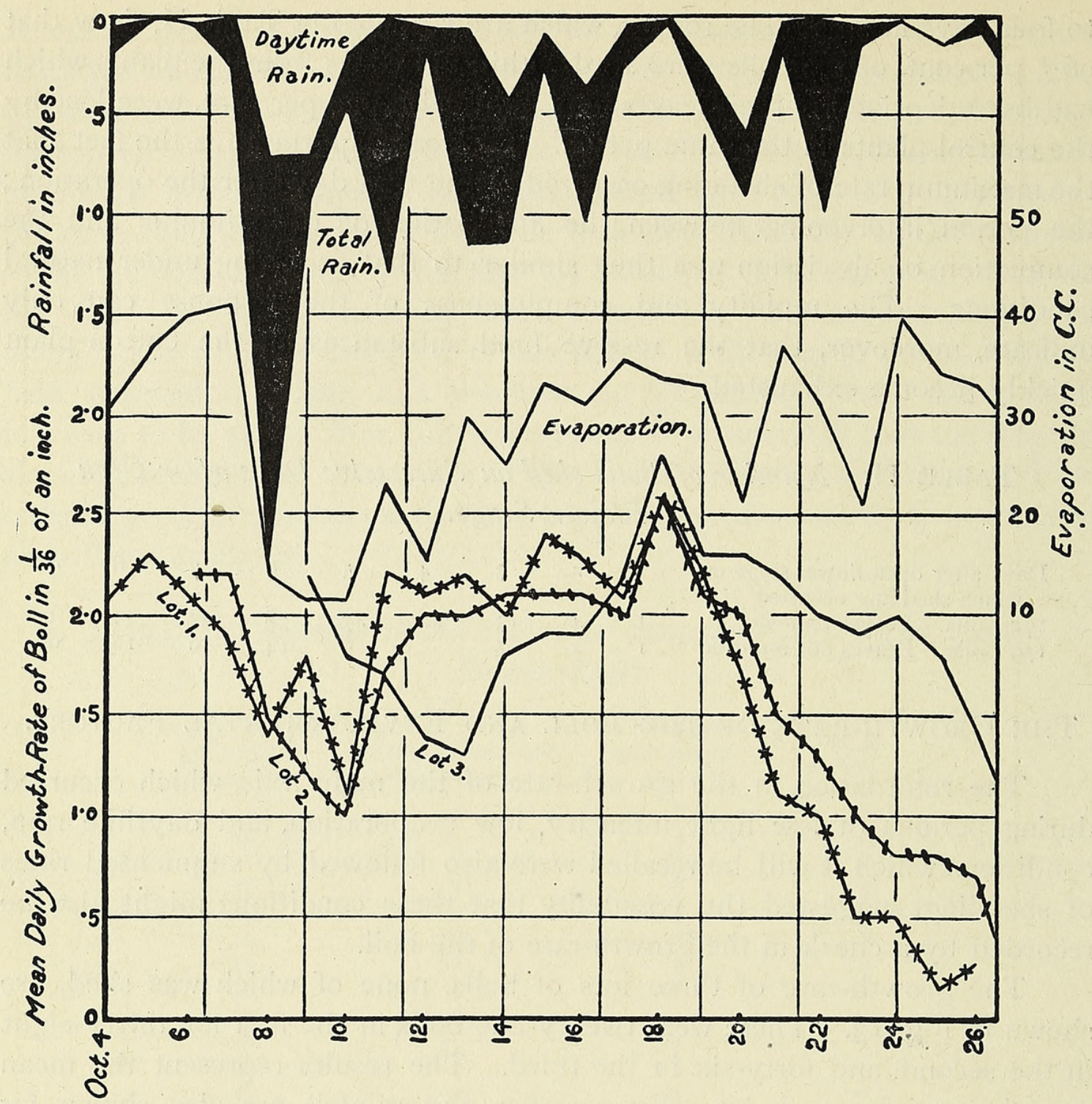

Fig. I3. Growth-rate of boll, evaporation, and rainfall.

The Growth-Rate of the Boll at Different Stages DURING THE Flowering PERIOD.

The results which are reproduced graphically in Fig. I4 were obtained by tagging sixty flowers (on the second group of plants) weekly throughout the flowering period and measuring daily the growth-rate made by each lot for the six days following the flowering stage. Bolls which were shed within this period are not included in the results; their number is shown on the graph within the circles. The coefficients of variability of the daily growth-rates and also the daily rate of boll-shedding for the whole group have also been included.

The continued decline in the growth-rate of lots $5,6,7$, and II is the first point deserving comment. It will be seen that this decline was accompanied by a marked increase in the coefficients of variability of the 


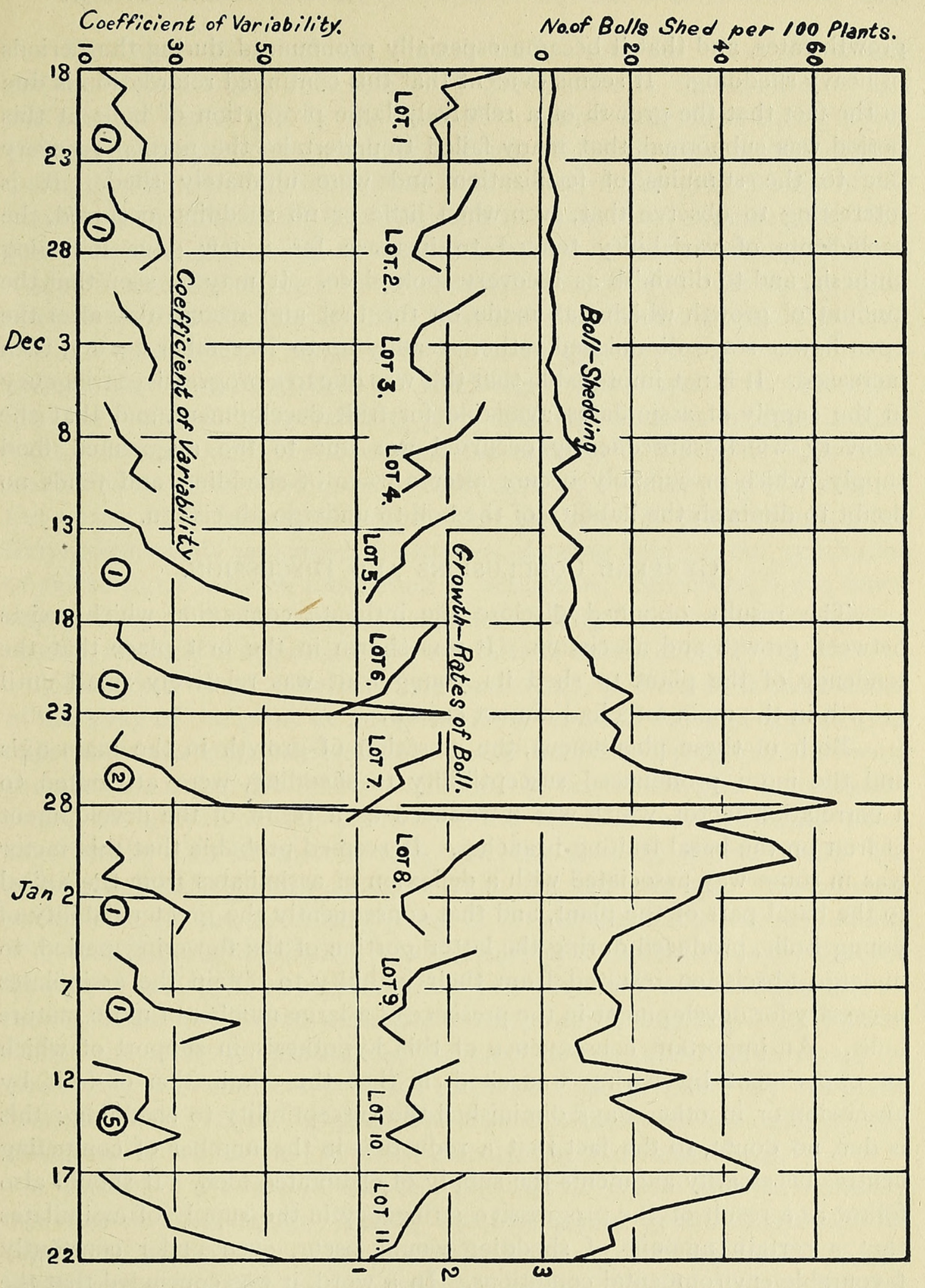

Mean Daily Growth -Rate of

Bolls in $\frac{1}{36}$ of an inch.

FIG. 14. Daily growth-rates of boll for six days. Coefficients of variability of daily growth-rates and daily rate of shedding for Gp. II. 
growth-rates, and that it became especially pronounced during the periods of heavy shedding. It seems evident that this continued retardation is due to the fact that the growth of a relatively large proportion of bolls at this period was subnormal, that many failed to undertake the normal recovery due to the stimulus of fertilization and were ultimately shed. It is interesting to observe that, even when little or no shedding occurred, the coefficients of variability tended to increase for a few days following anthesis, and to diminish as recovery took place. It may be seen that the amount of growth which was made on the first and second day after the open flower stage diminished rather steadily up to December 25 , and then increased. It is not improbable that this was due to a progressive stringency in the supply of assimilates available for fruit development, and that the recovery which subsequently occurred was due to the augmented food supply, which presumably occurs after a wave of shedding and tends no doubt to diminish the liability of the boll to undergo abscission.

\section{General Conclusions and Discussion.}

The results obtained disclose the intimate connexion which exists between growth and abscission. It was shown in the first place that the tendency of the plant to shed its young fruit was relatively small until growth in the main axis had almost ceased.

Both of these phenomena, the cessation of growth in the main axis and the more pronounced susceptibility to shedding, were attributed to a correlation factor, which was introduced as a result of the development of fruit on the basal fruiting branches. It seemed probable that this factor was in some way associated with a deflexion of assimilates from the apical to the basal part of the plant, and that consequently the greater liability of young bolls, produced during the latter portion of the flowering period, to undergo abscission resulted from their inability to obtain the assimilates necessary for development in the presence of a large number of more mature bolls. An important consequence of this hypothesis, in support of which an experiment by Ewing was cited, is that the elimination of fruit by abscission or in other ways diminished the susceptibility to shedding; this is due, no doubt, to the fact that a reduction in the number of competing centres necessarily augments the supply of elaborated food. It should also follow as a result of the progressive stringency in the supply of assimilates that a certain amount of shedding would occur, even under constantly favourable environmental conditions. In a word, it was concluded that the a mount of shedding which takes place during any given period is determined on the one hand by the rate at which food is elaborated by the plant and on the other by the rate at which it is withdrawn by the developing fruit, and that consequently the advent of any factor which tends to limit elaboration augments the rate of shedding. 
The next phase of the inquiry dealt with the effect of certain environmental factors upon the daily growth:rate of the main axis and the rates of shedding. It was found that dark, humid days, during which the rate of evaporation remained low and on which a great deal of rain generally fell, resulted in marked retardation in the growth-rate of the main axis, and that in the later stages of the plants' development they were the invariable precursors of augmented rates of boll-shedding. It was assumed that the occurrence of external conditions of this nature must operate to check the rate at which food was elaborated, and that this check was the cause both of the retardation in the growth-rate of the main axis and of the augmented rates of shedding. The absence of laboratory facilities rendered it impossible to place this hypothesis on an experimental basis. It was shown, however, that the removal of all the foliage leaves was followed within from three to eight days by the dropping of almost all the young fruit. It was also found that the removal of all except a few fruits considerably prolonged the interval elapsing between the application of the stimulus and the completion of abscission. Moreover, it was found that pruning off the fruit, and thereby diminishing the number of competing centres, resulted in augmented growth-rates of the main axis.

Inasmuch as previous work has consistently pointed to a water-deficit in the body of the plant as being the most constant cause of shedding, an experiment was made to determine whether incipient drying was sufficiently pronounced, under the humid conditions of St. Vincent, as to markedly retard the growth of the plant. As the result of measurements which were made both in the morning and the evening, it was found that growth was only slightly inhibited while the sun was up. This was not unexpected, for the desiccating power of the aerial environment is normally very small during the period in which cotton is cultivated in St. Vincent. In view of this, and the considerations just advanced, the conclusion seems inevitable that the growth-inhibition which precedes shedding in St. Vincent is not the result of pronounced incipient drying, but is due rather to a retardation in the rate at which assimilates are produced by the plant. It should be emphasized, however, that a series of abnormal saturation deficits would also check the rate at which carbohydrates are elaborated.

Finally, it was shown that the growth-rate of the boll fell normally into two distinct stages. During the first period growth continued for some four to five days after anthesis, but at a declining rate. Growth throughout this period was apparently in no way dependent on fertilization. During the second stage the rate increased until finally it declined. The initiation of this stage was found to be dependent on fertilization. It was concluded that the stimulus supplied by fertilization operated in some way to ensure a movement of assimilates into the boll. In the absence of fertilization the boll underwent a steady decrement in growth until it was 
finally shed. That the destruction of pollen by rain was responsible for a small proportion of the shedding there would seem to be no doubt, but the more generally constant cause, it was concluded, was due to an interruption in the supply of assimilates entering the boll during the critical stage of growth-retardation which followed anthesis. The occurrence of a check in the growth-rate at this period seemingly prevents a variable proportion of the bolls from undertaking the augmented growth of the second stage, in spite of fertilization. Inasmuch as the factors responsible for the movement of elaborated food in the plant are still quite unknown, it is useless to speculate as to why one boll is able to survive while a neighbouring one undergoes abscission. The phenomena of physiological correlation are presumably in some way responsible.

Before concluding, it is important to note that negative growth-rates are normally shown for some one to three days prior to the completion of abscission. It would seem that the failure to secure the normal supply of assimilates must diminish the water-absorbing power (7) of the boll until a stage is reached at which the tension in the water columns of the plant leads to a suction of water from the boll. It may well be that this is not only the cause of the negative growth-rates, but that it is actually the factor which initiates abscission. It will be evident that any factor which injures the boll-insect punctures, fungous diseases, \&c.-will bring about abscission, provided the injury is sufficiently pronounced as to interrupt the movements of elaborated food into the boll.

\section{SUMMARY.}

I. A survey was made of the external and internal factors affecting the shedding of bolls and flower-buds in St. Vincent.

2. The susceptibility to shedding is relatively small in the earlier stages of the flowering period, but becomes much more marked in the later stages. It was found that the susceptibility becomes especially pronounced after the occurrence of growth-cessation in the main axis.

3. Both the cessation of growth in the main axis and the augmented susceptibility to shedding were attributed to a correlation factor which tended to deflect the supply of elaborated food from the apical part of the plant to the fruit developing on the basal fruiting branches.

4. The growth rate of the main axis was retarded on overcast, humid days. Periods of daytime rain, low rates of evaporation, and little direct solar radiation were also the precursors of augmented rates of shedding.

5. The retardation in the growth-rate of the main axis and the augmented rates of shedding were both attributed to a check in the assimilative activity of the leaves. 


\section{Mason.-Growth and Abscission in Sea Island Cotton. 483}

6. Removal of the foliage leaves from plants on which there were a number of maturing bolls resulted in the abscission of 96.5 per cent. of the young bolls within a period of nine days. The interval between the operation and the maximum rate of shedding was approximately similar to that normally occurring between the causative environmental conditions (cf. 4) and the completion of abscission.

7. The growth-rate of the main axis was only slightly retarded during the hours of sunshine, from which it was concluded that incipient drying was not pronounced under the humid conditions of St. Vincent.

8. The growth-rate of the boll declined for some days following anthesis ; recovery was found to be dependent on fertilization.

9. It was concluded that the metabolic transformations which preceded the formation of the absciss layer were especially liable to be initiated during this period of growth-retardation.

I0. Negative growth-rates were generally shown by the boll for some one to three days prior to the completion of abscission. It was suggested that inability to secure the assimilates necessary for normal development diminished the water-absorbing power of the boll until a stage was reached at which the tension in the water-columns of the plant led to a suction of water from the boll. This, it seemed, was the cause not only of the negative growth-rates, but was actually the factor initiating abscission.

I I. The general conclusion was drawn that the proportion of shedding over any given period was the resultant of two opposing factors, the rate at which food was synthesized by the plant and the rate at which it was utilized in the maturation of the fruit; and that any check in the former augmented the rate of shedding.

I2. It was emphasized that any factor which injured the boll-fungous and bacterial diseases, insect depredations, \&c.-caused the shedding of the boll, provided the injury was sufficiently pronounced as to interrupt the translocation of food into the boll.

In conclusion, the writer wishes to record his indebtedness to Mr. C.A.M. Marshall for his indefatigable assistance throughout the progress of the work.

ST. Vincent, March 1922. 


\section{Mason.-Growth and Abscission in Sea Island Cotton.}

\section{LITERATURE.}

1. Balls, W. L. (1912): The Cotton Plant in Egypt. London. (1915): The Development and Properties of Raw Cotton. London.

2. Ewing, E. C. (1918): A Study of Certain Environmental Factors and Varietal Differences influencing the Fruiting of Cotton. Miss. Agr. Exp. Sta., Tech. Bull., No. 8, pp. I-92.

3. Harland, S. C. (1917): Manurial Experiments with Sea Island Cotton in St. Vincent, with some Notes on Factors affecting the Yield. West Indian Bull., xvi. 169-202.

4. Livingston, B. E., and Brown, W. H. (1912): The Relation of the Daily March of Transpiration to Variations in the Water-Content of Foliage Leaves. Bot. Gaz., liii. 309-30.

5. Livingston, B. E. (1915): Atmometry and the Porous Cup Atmometer. Plant World, xviii. 2I-30, 5I-74, 95-III, II 3-40.

6. Lloyd, F. E. (1920): Environmental Changes and their Effect upon Boll-Shedding in Cotton. Ann. New Y.ork Acad. Sci., xxix. I-I 3 I.

7. Mason, T. G. (1921): The Water-Balance of the Plant and its Significance in Crop Production. West Indian Bull., xviii. ${ }_{5} 57-84$.

8. (1922): Growth and Correlation in Sea Island Cotton. West Indian Bull., xix. $214-38$. 


\section{$2 \mathrm{BHL}$ Biodiversity Heritage Library}

Mason, T. G. 1922. "Growth and abscission in sea island cotton." Annals of botany 36, 457-484. https://doi.org/10.1093/oxfordjournals.aob.a089817.

View This Item Online: https://www.biodiversitylibrary.org/item/234428

DOI: https://doi.org/10.1093/oxfordjournals.aob.a089817

Permalink: https://www.biodiversitylibrary.org/partpdf/319054

\section{Holding Institution}

Smithsonian Libraries

\section{Sponsored by}

Biodiversity Heritage Library

\section{Copyright \& Reuse}

Copyright Status: Not in copyright. The BHL knows of no copyright restrictions on this item.

This document was created from content at the Biodiversity Heritage Library, the world's largest open access digital library for biodiversity literature and archives. Visit BHL at https://www.biodiversitylibrary.org. 